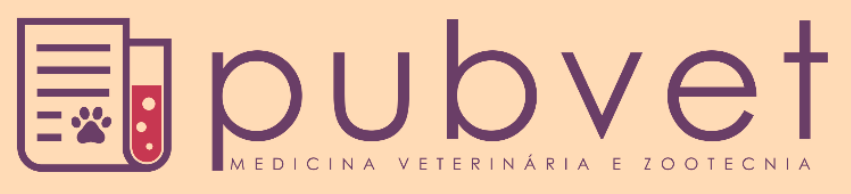

https://doi.org/10.31533/pubvet.v16n02a1048.1-11

\title{
Doença de Lyme canina: Relato de caso
}

\author{
Mayara Vieira Duarte da Paz ${ }^{1 *}$, Milton Kolber $^{2}$, Cristiane Mathias Soares ${ }^{3}$, Lucas Delfino \\ Soares $^{3}$, Thais Vieira de Souza ${ }^{4}$ \\ ${ }^{1}$ Graduanda em Medicina Veterinária - Universidade Metodista de São Paulo. Ribeirão Pires - SP. Brasil \\ ${ }^{2}$ Orientador - Prof. Dr. em Epidemiologia Experimental Aplicada às Zoonoses pela Universidade de São Paulo. SP. Brasil. \\ ${ }^{3}$ Co-orientador(a). Médico (a) Veterinário $(a)$ autônomo(a). Ribeirão Pires - SP. Brasil. \\ ${ }^{4}$ Co-orientadora. Mestre em Biotecnociência - São Caetano do Sul - SP. Brasil. Universidade Federal do ABC. \\ *Autor para correspondência,E-mail: mayara-vieira-paz,1@hotmail.com
}

Resumo. A doença de Lyme é pouco diagnosticada, apesar de frequente no mundo. Apresenta potencial zoonótico e os cães são considerados sentinelas da doença. Este trabalho tem como finalidade relatar um caso de um animal da raça Poodle atendido em uma clínica veterinária particular em Ribeirão Pires - SP, positivo para a presença de anticorpos de Borrelia burgdorferi confirmados através de sorologia pelo método Dot-Blot e teste rápido. $\mathrm{O}$ animal estava realizando exames pré-cirúrgicos para retirada de um tumor em região anal, não apresentava alterações no exame físico, sendo a trombocitopenia única desordem observada. O diagnóstico é fechado através da sorologia juntamente com a clínica/ histórico do animal, mas na maioria dos casos é um achado clínico. Como a borreliose, outro nome para doença de Lyme, tem sinais inespecíficos e de grande importância para a saúde pública, é essencial que seja incluída como diagnóstico diferencial de demais doenças com sintomas semelhantes, embora a mesma já foi relatada associada a Erliquiose, Anaplasmose e entre outras hemoparasitoses transmitidas através do carrapato. Este trabalho tem caráter informativo e de educação sanitária e epidemiológica, dando oportunidade aos leitores conhecerem mais profundamente a doença e seus riscos à saúde pública.

Palavras-chave: Carrapato, diagnóstico, doença de lyme, zoonose

\section{Canine Lyme disease: Case report}

\begin{abstract}
Lyme disease is underdiagnosed, although it is common worldwide. It has zoonotic potential and dogs are considered sentinels of the disease. This paper aims to report a case of a Poodle animal treated at a private veterinary clinic in Ribeirão Pires - SP, positive for the presence of antibodies to Borrelia burgdorferi confirmed by serology by the Dot-Blot method and rapid test. The animal was undergoing pre-surgical exams to remove a tumor in the anal region, it did not present alterations in the physical exam, and thrombocytopenia was the only disorder observed. The diagnosis is made through serology together with the clinical/clinical history of the animal, but in most cases it is a clinical finding. As borreliosis has nonspecific signs and is of great importance to public health, it is essential that it be included as a differential diagnosis of other diseases with similar symptoms, although it has been reported associated with Ehrlichiosis, Anaplasmosis and other tick-borne hemoparasitosis.This work has an informative and sanitary and epidemiological education character, giving the opportunity to readers to know more deeply about the disease and its risks to public health.
\end{abstract}

Keywords: Tick, diagnosis, lyme disease, zoonosis

\section{Enfermedad de lyme canina: Reporte de caso}

Resumen. La enfermedad de Lyme es poco diagnosticada, aunque es común en todo el mundo. Tiene potencial zoonótico y los perros se consideran centinelas de la enfermedad. 
Este trabajo tiene como objetivo reportar un caso de un animal Poodle tratado en una clínica veterinaria privada en Ribeirão Pires - SP, positivo para la presencia de anticuerpos contra Borrelia burgdorferi confirmado por serología por el método Dot-Blot y prueba rápida. El animal estaba siendo sometido a exámenes prequirúrgicos para extirpar un tumor en la región anal, no presentaba alteraciones en el examen físico y la trombocitopenia fue el único trastorno observado. El diagnóstico se realiza mediante serología junto con la historia clínica del animal, pero en la mayoría de los casos es un hallazgo clínico. Dado que la borreliosis, otra denominación de la enfermedad de Lyme, tiene signos inespecíficos y es de gran importancia para la salud pública, es fundamental que se incluya como diagnóstico diferencial de otras enfermedades con síntomas similares, aunque se ha reportado asociada con Ehrlichiosis, Anaplasmosis y entre otras hemoparasitosis transmitidas a través de la garrapata. Este trabajo tiene un carácter informativo y de educación sanitaria y epidemiológica, dando la oportunidad a los lectores de conocer más a fondo la enfermedad y sus riesgos para la salud pública.

Palabras clave: Garrapata, diagnóstico, enfermedad de Lyme, zoonosis

\section{Introdução}

A doença de Lyme é uma infecção multissistêmica, causada pela bactéria Borrelia burgdorferi, transmitida pelos carrapatos, podendo acometer cães, gatos e até mesmo o homem. Essa doença tem distribuição mundial (Littman et al., 2006; Tilley et al., 2008). Os sinais clínicos, na grande maioria dos casos são inespecíficos, e os animais apresentam febre, letargia, linfoadenomegalia e trombocitopenia, alterações que podem ser indicativas de outras doenças (Elhelw et al., 2021). Os transmissores são os Ixodes e possivelmente o Amblyomma e a bactéria espiroqueta vai se disseminar no hospedeiro pela união ao plasminogênio sem ativadores na ativação do complemento e resistência ao soro também, seguindo por uma resposta inflamatória desencadeada pelas lipoproteínas. O término das manifestações clínicas indicará atividade humoral específica de anticorpos (Maluf Júnior et al., 2007). Essas condições são pouco relatadas em animais com a doença de Lyme (Borys et al., 2019). A minoria dos animais desenvolve a doença clínica, por esse motivo, esse agravo é pouco diagnosticado e, portanto, pouco controlado (Gettings et al., 2019). É dever do médico veterinário, orientar a população sobre o controle de vetores, já que os mesmos são os responsáveis pela transmissão da borreliose (Burgess, 1986).

Esse relato de caso, pretende mostrar a história clínica do animal descrito e os estudos sobre a doença retratada com o objetivo de trazer novas informações aos veterinários.

\section{Descrição de caso}

Um cão, macho, fértil, de 12 anos de idade, da raça Poodle, foi atendido em dezembro de 2020, em uma clínica veterinária particular em Ribeirão Pires, São Paulo. O animal estava realizando exames précirúrgicos para a retirada de nódulo em região anal. Fora o problema que levou o animal à clínica, o exame físico estava dentro da normalidade. Todavia, os exames laboratoriais evidenciaram uma trombocitopenia confirmada por microscopia $48.000 / \mathrm{mm}^{3}$ e um leve aumento dos leucócitos totais de $20.100 / \mathrm{mm}^{3}$ (Tabela 1), com neutrofilia e eosinofilia, sendo que não havia alterações morfológicas. O exame bioquímico estava dentro da normalidade, somente com a FAL aumentada (185 U/l).

Tabela 1. Leucograma e plaquetas de um cão, macho de 12 anos de idade, da raça Poodle atendido em clínica veterinária em Ribeirão Pires, São Paulo

\begin{tabular}{lccc}
\hline & & Meses & \\
& & Fevereiro & Março \\
\hline Leucócitos, Milhares $/ \mathrm{mm}^{3}$ & 20.100 & 23.800 & 22.200 \\
Bastões & 0 & 0 & 0 \\
Neutrófilos & $72 \%-14.472$ & $78 \%-18.500$ & $63 \%-13.986$ \\
Linfócitos & $17 \%-3.417$ & $16 \%-3.900$ & $25 \%-5.550$ \\
Monócitos & $3 \%-603$ & $0-0$ & $4 \%-888$ \\
Eosinófilos & $8 \%-1.608$ & $6 \%-1.400$ & $8 \%-1.608$ \\
\hline Plaquetas, Milhares $/ \mathrm{mm}^{3}$ & 48.000 & 25.000 & 32.000 \\
\hline
\end{tabular}


Suspeitou-se de erliquiose, devido a trombocitpenia e solicitado o exame snap 4DX (Dirofilaia immitis, Ehrlichia canis, Ehrlichia ewingii, Anaplasma phagocytophilum, Anaplasma platys e $B$. burgdorferi) (Figura 1). O exame resultou positivo para a presença de anticorpos para B. burgdorferi.

O tratamento foi iniciado com Doxiciclina $80 \mathrm{mg} / \mathrm{kg} 1 / 2$ comprimido BID, durante 30 dias. Em fevereiro, o animal retornou apresentando sangramento do tumor, foi coletado novo hemograma evidenciando a piora da trombocitopenia $25.000 / \mathrm{mm}^{3}$ e leucocitose de $23.800 \mathrm{mil} / \mathrm{mm}^{3} \mathrm{com}$ neutrofilia e monocitose.

No retorno do mês de março, o animal ainda apresentava trombocitopenia severa. No entanto, melhor que no exame anterior $32.000 \mathrm{mil} / \mathrm{mm}^{3}$ e leucograma com leucocitose $22.200 / \mathrm{mm}^{3}$ por neutrofilia e eosinofilia, foi então recomendado aumento da dose de doxiciclina $100 \mathrm{mg} / \mathrm{kg}$ para $3 / 4$ de comprimido $\mathrm{BID}$, durante 30 dias, já que não estava respondendo ao tratamento conforme o esperado.

Em maio o animal havia encerrado o tratamento com o antibiótico, estava estável e foi coletado novo hemograma e sorologia para Borrelia burgdorferi. As plaquetas estavam dentro dos valores de referência $244.000 / \mathrm{mm}^{3}$ com morfologia preservada. A sorologia foi feita através Dot Blot - Elisa, apresentando o resultado positivo (Figura 2), confirmando assim a Doença de Lyme. O tratamento terminou, e agora o animal fará o acompanhamento para a observação de recidivas.

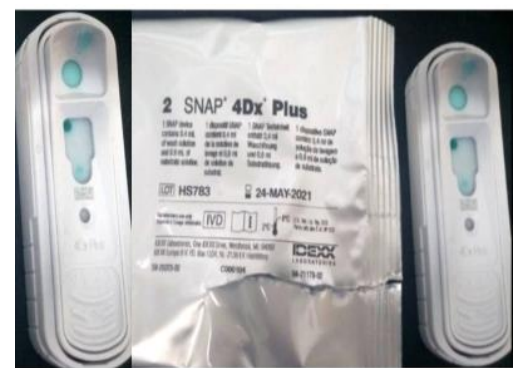

Figura 1. Teste positivo para anticorpos contra Borrelia burgdorferi.

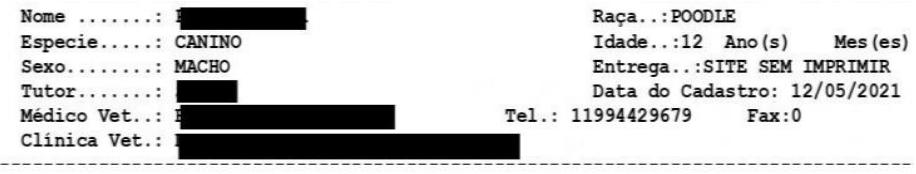

DOENÇA DE LYME

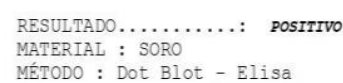

Figura 2. Sorologia para anticorpos contra Borrelia burgdorferi.

\section{Discussão}

Doença de Lyme (DL) ou borreliose é uma doença infecciosa não contagiosa, emergente, multissistêmica de distribuição mundial, com potencial zoonótico (Elhelw et al., 2021). É a principal doença transmitida por vetores no hemisfério Norte (Irwin et al., 2017). Causada por uma bactéria espiroqueta gram-negativa (Schreiber et al., 2014), pode acometer cães e humanos acidentalmente, onde ambas as espécies poderão sofrer consequências clínicas. A cronicidade da doença de Lyme em humanos, representa um potencial de gravidade, motivando a necessidade de mais estudos sobre a incidência e distribuição da doença de forma precisa (Liu et al., 2019).

A transmissão ocorre pelos carrapatos da família ixodídae na forma transovariana e/ou transestadial (Lappin et al., 2015). O I. ricinus é o principal vetor na Europa, transmitem a infecção tanto na fase ninfa, como na fase adulta (Galluzzo et al., 2020). No Brasil, o Rhipicephalus sanguineus, é a espécie de carrapato que mais infestam os cães nas áreas urbanas, enquanto o Amblyoma é mais encontrado em cães na zona rural, suspeita-se que estes também estão envolvidos na transmissão da Borrelia burgdorferi (Vieira et al., 2013).

Os carrapatos Ixodes tem ciclo evolutivo em quatro estágios: ovos, larvas, ninfas e adultos (Kassab et al., 2020). A pré-postura é única e depende das condições climáticas; temperaturas menores que $15^{\circ} \mathrm{C}$, retardam e temperaturas acima de $27^{\circ} \mathrm{C}$ podem acelerar a postura (Fortes, 2004). O ciclo de vida é de 2 anos aproximadamente, e tendo como exemplo o clima nos Estados Unidos, o ciclo pode ocorrer da seguinte maneira; as larvas eclodem na primavera, tornando-se infectantes e se alimentam em camundongos que acabam sendo infectados. As larvas se transformam em ninfas e chegam à adultas ao final do outono do segundo ano, então as fêmeas acasalam em outros mamíferos, ingurgitam e caem ao solo, se escondendo embaixo de folhas até a primavera seguinte, e cada uma colocará cerca de 2.000 ovos, enquanto os machos tendem a permanecer no mamífero (Bowman, 2010). Na maioria das vezes, é o macho que vai atrás da fêmea para acasalar, e um único macho pode fertilizar várias fêmeas (Fortes, 2004). 
A Borrelia burgdorferi (Figura 3) está classificada na ordem Spirochaetales, família Spirochetaceae, apresentando-se na forma espiral, podendo ter de 7 - 14 flagelos na sua extremidade, responsável pela sua mobilidade e com uma parede celular de 10-30 $\mu \mathrm{m}$ de comprimento e 0,2-0,3 $\mu \mathrm{m}$ de diâmetro (Kassab et al., 2020).

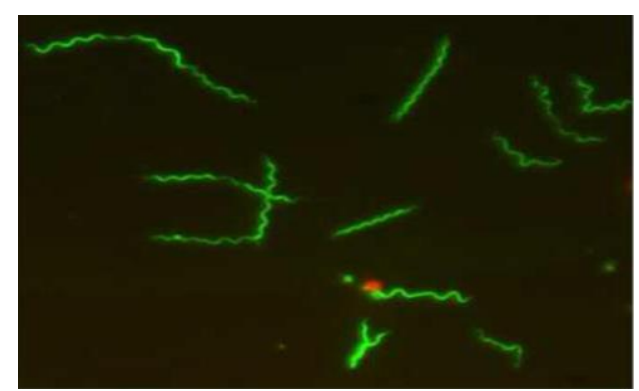

Figura 3. Espiroqueta de Borrelia burgdorferi corada com Syto 9 e visualizada através de microscopia fluorescente. Fonte: Murray \& Feder (2001)

Existem pelo menos 16 genoespécies diferentes de Borrelia (Schreiber et al., 2014). Filogeneticamente, o gênero da Borrelia pode ser separado em dois grupos. O grupo 1, Borrelia de Lyme, e o grupo 2, formado pela Borrelia miyamotoi, Borrelia hermsii, Borrelia parkeri e Borrelia turicatae. Esse último grupo tem grande importância na medicina nos Estados Unidos, já que é responsável pela febre recorrente, transmitida pelos "carrapatos moles" (Ornithodoros hermsi, Ornithodoros parkeri e Ornithodoros turicata transmitindo B. hermsii, B. parkeri e B. turicatae) (Gettings et al., 2019). Cães infectados pela B. turicatae, B. hermssi e B. persica, indicam manifestações clínicas semelhantes (Baneth et al., 2016).

Segundo Baneth et al. (2016), no estudo sobre infecções por Borrelia persica, realizado na Califórnia entre 2003-2015, foi feito um levantamento filogenético, comparando 267 sequências de DNA, através de exame PCR para o sequenciamento de partes dos genes da flagelina (flab), 16S rRNA e glicerofosfodiéster fosfodiesterase (GlpQ). Evidenciou-se que as sequências de B. persica agrupam entre si, assim como a localização e genótipo (Figura 4), os demais tipos de Borrelia agrupam-se de outra forma.

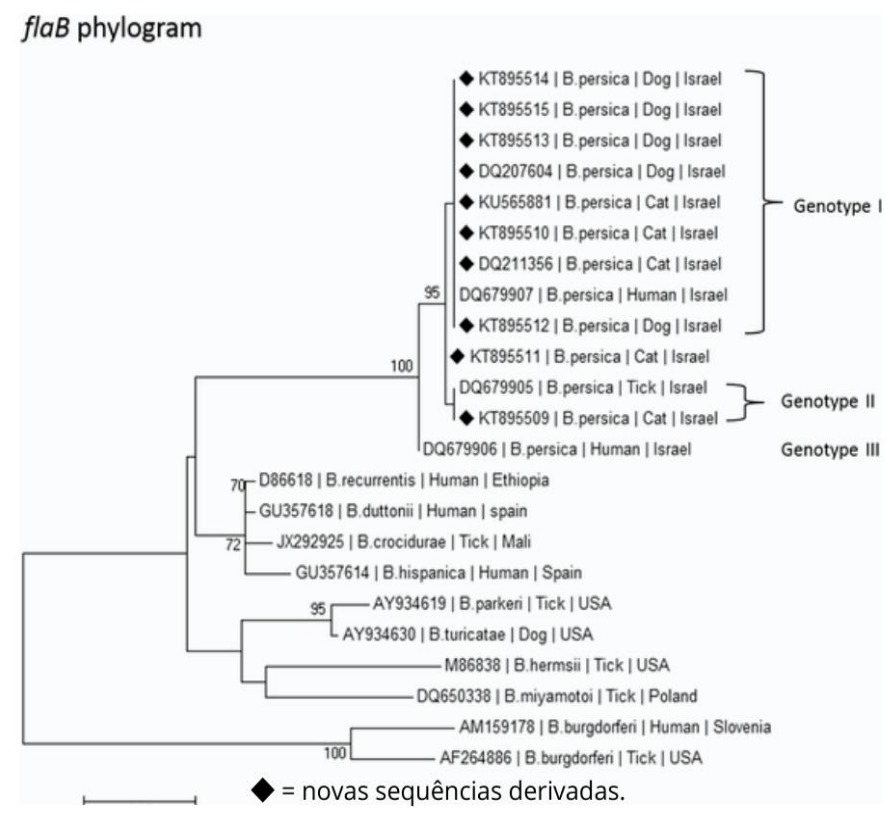

Figura 4. Análise filogenética da Borrelia spp. Fonte: Baneth et al. (2016).

De acordo com Dewage et al. (2019), Lieske \& Lloyd (2018) e Liu et al. (2019), alguns fatores associados aos vetores, como: densidade de ninfas infectadas, presenças de reservatórios e hospedeiros de manutenção, clima, paisagem e ambiente, densidade demográfica, dados socioeconômicos e localização geográfica, podem interferir no risco de infecção. 
O tempo de transmissão da espiroqueta da DL para o carrapato pode variar e depender de vários fatores, como até mesmo a saúde do hospedeiro, mas normalmente, ele se alimenta por vários dias, exigindo um período de alimentação de 24 a 72 horas segundo Izac \& Marconi (2019), em média, até 50 horas de repasto (Nelson \& Couto, 2015).

Canídeos e felídeos podem se infectar pela Borrelia, servindo como sentinelas para a doença de Lyme humana (Baneth et al., 2016). Conforme aumenta a interação entre hospedeiros mamíferos e pessoas, o risco de propagação de doenças zoonóticas aumenta proporcionalmente (Toepp et al., 2018). Facilmente, podemos encontrar carrapatos em habitats de florestas, com vegetação e lugares alagadiços. Todavia, também é possível serem vistos em parques urbanos. Por esse fato, cães vadios e abrigados são considerados um risco significativo para à saúde pública, sendo um problema conhecido, mas subestimado em vários locais como países da América do Norte e Europa (Galluzzo et al., 2020). Algumas citações, reconhecem a dispersão de carrapatos imaturos através de aves migratórias (Lieske \& Lloyd, 2018).

Os sinais clínicos podem ser diferentes de acordo com a espécie de Borrelia. Somente 5-15\% dos animais infectados costumam apresentar sintomas, sendo assim, podemos perceber uma subestimação significativa da prevalência da doença (Elhelw et al., 2021). Em cães de experimentação, o período de incubação foi de 2 a 5 meses (Bowman, 2010). A borreliose canina, costuma não ter manifestações clínicas específicas, comumente é observada letargia, claudicação, febre, anorexia, linfadenopatia, mas em alguns casos mais graves, os animais podem apresentar artrite e disfunções neurológicas (ㅁalluzzo et al., 2020).

Segundo Baneth et al. (2016) a trombocitopenia, anemia ou neutrofilia podem estar presentes no hemograma, e de acordo com Borys et al. (2019) evidências bioquímicas de azotemia, associada a hiperfosfatemia e hipercalemia, podendo ainda apresentar hematúria, glicosúria e piúria com urocultura negativa podem ser resultados laboratoriais de animais positivos para a doença de Lyme. Demais achados como a espiroquetemia profunda (Figura 5) é capaz de ser evidente no esfregaço sanguíneo nos animais que aparentam letargia, desenvolvem anemia e trombocitopenia (Baneth et al., 2016).

A neuroborreliose, apesar de ser considerada rara, é um diagnóstico diferencial em animais que apresentam alterações de SNC em regiões endêmicas (Nelson \& Couto, 2015). No relato de caso de suspeita de borreliose descrito por Ferreira et al. (2016), o animal chegou a apresentar midríase bilateral permanente por 4 dias; porém a falta de testes não expressa segurança para indicar relação com a infeção por Lyme, apesar de o animal apresentar o teste de Elisa positivo para anticorpos de B. burgdorferi.

À medida que a doença progride, a claudicação e a poliartrite intermitentes podem ser comuns, como também a conjuntura com micro lesões e inflamação dos tecidos, membranas articulares, cápsulas articulares e bainhas de tendões, assim como a meningite, vasculite linfoplasmocítica, hiperqueratose e perineurite (Marconi et al., 2020). Filhotes entre 6 a 12 semanas, podem desenvolver poliartrite autolimitante recorrente. Nas análises citológicas de líquidos sinoviais das poliartrites agudas, podem ser observadas uma inflamação neutrofílica (Nelson \& Couto, 2015). A artrite não erosiva é uma das principais manifestações clínicas, na maioria das vezes, de aparência brutal e intermitente em uma única articulação, sendo o carpo a mais acometida (Moraillon et al., 2013). A manqueira pode durar cerca de 3 a 4 dias, o animal poderá andar de forma rígida, com o dorso arqueado, estando sensível ao toque (Bowman, 2010).

Acredita-se que a síndrome renal "Nefrite de Lyme" ocorra entre 5 - 10\% dos cães, enquanto nos humanos, essa manifestação é rara (Borys et al., 2019). Em cães da raça Labrador e o Golden Retriever, esse distúrbio pode ser mais comum, comparado a outras raças (Nelson \& Couto, 2015). Ainda assim, a soropositividade para o agente infeccioso, concomitante com proteinúria, observada somente em $2 \%$ dos casos, com sugestão de doença glomerular, não confirma a relação causa/efeito de imuno complexos de Lyme, mesmo se sinais clínicos como a claudicação forem observados, já que não existe nenhuma técnica de coloração assegurada para provar essa teoria (Littman et al., 2006).

Em cães com doença de Lyme, foram identificados bloqueios AV de terceiro grau (completo) e de segundo grau de alta intensidade. Alguns ainda apresentaram síncope, ICC, redução da contratilidade miocárdica e arritmias. Infiltrados de células plasmáticas, macrófagos, neutrófilos e linfócitos indicaram lesões miocárdicas patológicas devido à Borrelia burgdorferi (Nelson \& Couto, 2015). A taquicardia 
ventricular também pode ser causada pela doença de Lyme (Rabelo, 2012). Todavia, a incidência de comprometimento cardíaco, ainda é desconhecida (Tilley, 2008).

O diagnóstico de borreliose nos cães é difícil por conta do baixo número de animais que desenvolvem a doença clínica (Gettings et al., 2019). O PCR que detecta o DNA da Borrelia burgdorferi, é prejudicado devido ao número reduzido de espiroquetas nas amostras clínicas, sendo assim, o método de diagnóstico mais indicado são os sorológicos (Oldenburg et al., 2020). Os testes sorológicos comumente utilizado nos cães para determinar a exposição a B. burgdorferi e para diagnosticar borreliose, em conjunto com outros testes, tem finalidade para detectar a proteinúria e anticorpos contra o peptídeo C6, via testes quantitativos. Todavia, não é possível distinguir a infecção ativa da exposição antiga, pois o anticorpo contra o peptídeo sintético C6 pode permanecer por meses a anos (Gettings et al., 2019; Oldenburg et al., 2020).

De 10 a 30\% dos cães caçadores, possuem anticorpos para B. burgdorferi sem expressarem sinais clínicos, sendo assim, é necessário obter os títulos de $\operatorname{IgG}$ e IgM simultaneamente para datar o contato com a bactéria, já que a imunoglobulina $\mathrm{G}$ persistem por vários anos, mostrando um contato antigo e podem ser encontradas em grande número em animais, enquanto a imunoglobulina $\mathrm{M}$, mostra um contato recente, mas não aparecerá antes de 4 semanas e pode persistir até 9 meses. Ainda assim, quando existe uma forte suspeita clínica e o cão é soronegativo, pode ser realizada uma segunda sorologia 4 a 6 semanas após e comparar as taxas diferentes (Moraillon et al., 2013).

Podem ser levantadas 4 hipóteses para explicar a infecção transmitida por carrapatos, no caso de sorologia positiva para o anticorpo de Borrelia burgdorferi: (1) sorologia falso-positiva, (2) exposição em viagens para lugares endêmicos, (3) infestação pelo carrapato, e (4) dispersão aviária de carrapato (Lieske \& Lloyd, 2018).

A reação cruzada entre a $B$. turicatae e $B$. burgdorferi, podem ocorrer nos testes de IFA, mas não nos testes que utilizam a proteína C6 (Gettings et al., 2019). Já no teste 4 DX ${ }^{\circledR}$ IDEXX ELISA, Lieske \& Lloyd (2018) evidenciaram uma especificidade de aproximadamente 100\%, 98,8\% (Evason et al., 2019).

O método Western blot, considerado o padrão ouro, indica infecção ou exposição caso a presença de 3 a 6 bandas sejam identificadas, evidenciando a produção de anticorpos contra diversas proteínas específicas, caracterizando uma infecção natural e não causada pela vacinação (Vaden et al., 2013). Para a determinação do diagnóstico, é importante a combinação entre histórico clínico, sinais e sintomas, exames complementares como testes sorológicos e titulações de anticorpos. Também é necessário a exclusão de outras causas conhecidas e ter uma resposta terapêutica (Nelson \& Couto, 2015).

Estima-se que 5\% dos animais infectados, podem ter uma coinfecção, e assim terão mais chances de desenvolver a doença, como na análise realizada no Canadá, relatando casos de coinfecções entre $B$. burgdorferi e Anaplasma spp., devido ao vetor semelhante, onde teve uma prevalência de 4,1\% dessas infecções concomitantes (Evason et al., 2019). É comum a infecção simultânea entre Lyme, Ehrlichia, Anaplasma e a febre maculosa das montanhas, onde ambas apresentaram sinais clínicos semelhantes (Vaden et al., 2013).

Em humanos, é difícil a associação com as doenças crônicas à infecção por Borrelia. Atualmente, já se reconhecem complicações reumatológicas, neurológicas e cardíacas, assim como a fibromialgia, comprometimento da memória e fadiga crônica, mas o diagnóstico definitivo para borreliose permanece incerto (Borys et al., 2019). Já na fase aguda, pode surgir o eritema migratório no local da picada do carrapato (Figura 6), sintomas compatíveis com o de uma gripe, cefaleia, calafrios, mialgia, febre, também poderão aparecer lesões disseminadas, chamadas de eritema anular secundário (Yoshinari et al., 2010).

Assim, como para os animais, os carrapatos Ixodes podem transmitir outros patógenos simultaneamente ou separadamente para os humanos, como por exemplo a Babesiose, Anaplasmose, outras espécies de Borrelia e alguns tipos de vírus (Liu et al., 2019).

Animais que iniciam o tratamento com antibioticoterapia rapidamente, costumam ter desaparecimento da espiroquetemia e ligeira recuperação. Em alguns estudos, foram relatados o sucesso do uso de Amoxicilina associada ao ácido clavulânico, mas a Doxiciclina é recomendada como medicamento de primeira eleição, já que também é sugerida para o tratamento humano, demonstra ser 
eficaz para diminuir os sinais clínicos, ser de fácil administração e apresentar eficácia contra coinfecções (Baneth et al., 2016; Littman et al., 2006). A dose de Doxiciclina oral recomendada é de $5 \mathrm{mg} / \mathrm{kg}$ a 10 $\mathrm{mg} / \mathrm{kg}$ a cada doze horas, por pelo menos quatro semanas. Se o quadro for agudo, a melhora clínica precisa ser visível em até 3 dias após o início da medicação (Crivellentin \& Borin-Crivelletin, 2015; Nelson \& Couto, 2015).

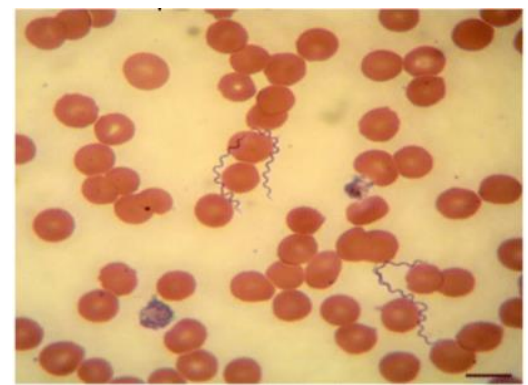

Figura 5. Espiroqueta de Borrelia persica em esfregaço sanguíneo de cão. Coloração Romanowsky. Barra de escala $10 \mu \mathrm{m}$. Fonte: Baneth et al. (2016).

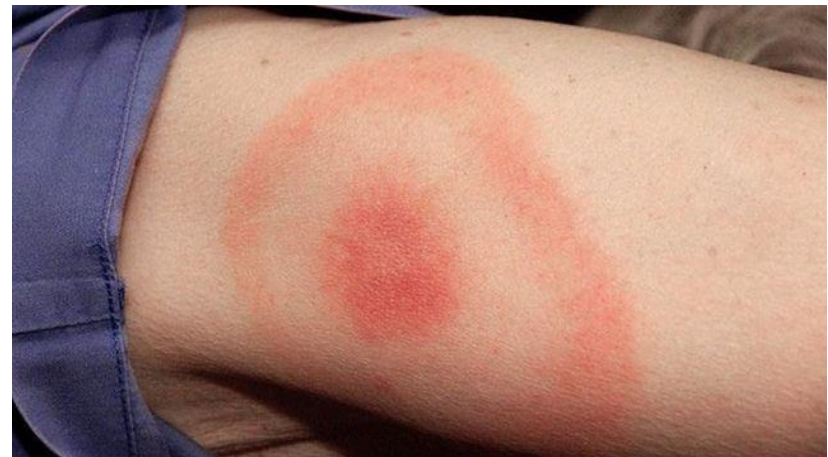

Figura 6. Eritema Migratório devido à picada de carrapato. Fonte: Centers for Disease Control and Prevention (CDC, 2020).

Segundo Littman et al. (2006), a Doxiciclina não foi associada a perda da coloração dentária em crianças, sendo assim, atualmente, já foi liberada a utilização da mesma em alguns países, nos filhotes a partir de 4 semanas de vida. Outros autores, como Bowman (2010) relembram os cuidados para administrar esse antibiótico em cães jovens, já Spinosa et al. (2017) evidenciam a capacidade das tetraciclinas se ligarem ao cálcio, podendo causar deposição nos tecidos ósseos e dentes, sendo assim não é indicada em fêmeas prenhas e filhotes em fase de crescimento.

A azitromicina, pode ser administrada, via oral, em dose igual a $25 \mathrm{mg} / \mathrm{kg}$ a cada 24 horas, entre 10 a 20 dias, para essa enfermidade, ou também pode ser escolhida a Amoxicilina na dose de $20 \mathrm{mg} / \mathrm{kg}$, pela via oral, em intervalos de até oito horas, por até 20 dias (Crivellentin \& Borin-Crivelletin, 2015). Analgésicos, como a gabapentina, também podem fazer parte do tratamento, conforme a necessidade do paciente, caso apresente dor neuropática. Antiinflamatórios não esteroidais, não são indicados de início, a fim de diminuir a possível formação de úlcera gástrica, e sim priorizados em quadros de poliartropatia imunomediada não responsiva (Littman et al., 2006).

Na seção VLsE do genoma das espiroquetas, podem ocorrer algumas recombinações genéticas produzindo lipoproteínas de superfícies antigenicamente distintas o que poderá levar a uma maior sobrevida da bactéria para um desenvolvimento de uma infecção crônica e subclínica. Desse modo, as espiroquetas podem ficar latentes no tecido conectivo e músculos durante anos, mesmo após a terapia com antibióticos, e nenhum teste atualmente tem a capacidade de diferenciar uma infecção autolimitante anterior, infecção subclínica ou ainda uma infecção ativa (Vaden et al., 2013).

A forma mais econômica de prevenção para as doenças infecciosas é a vacinação, mas as estratégias de tratamento e diagnóstico preciso, também são fundamentais (Izac \& Marconi, 2019). Os animais domésticos desempenham um papel significante na transmissão de doenças zoonóticas, sendo responsáveis por mais de 75\% dos patógenos humanos emergentes (Toepp et al., 2018). Combinações de mecanismos de profilaxia, podem ser utilizadas, como por exemplo os medicamentos orais e tópicos, já que é importante o controle do carrapato, não só para prevenir a Borrelia, como outras doenças transmitidas por esse parasita (Littman et al., 2006).

No momento, existem dois tipos de vacinas contra a Doença de Lyme, a subunidade e a bacterina. A bacterina é formada através de lisados de duas cepas de espiroquetas de DL cultivadas em laboratório, enquanto a vacina do tipo subunidade, consistem na utilização de proteínas combinadas, altamente purificadas (OspA e ou OspC) (Izac \& Marconi, 2019).

De acordo com a Força-Tarefa AAHA, cães que forem viajar para locais endêmicos, ou residentes em áreas onde o risco de exposição a $B$. burgdorferi for elevada à crescente, a vacinação pode ser indicada, sendo necessário duas doses de vacina em um intervalo de duas a quatro semanas, e é importante que o protocolo termine duas a quatro semanas antes da viagem (Ford, 2001). 
Como diagnóstico diferencial, outras artrites inflamatórias não erosivas, precisam ser descartadas, e também é necessário excluir algumas doenças infecciosas sendo elas: febre maculosa, erliquiose, histoplasmose, criptococose, blastomicose, leishmaniose, infecção por Streptococcus ou Staphyloccocus e outras doenças imunomediadas, como o lúpus eritematoso. É importante diferenciar de Hemartrose e doenças de raças específicas como a Artrite do Akita, febre do Shar Pei (Bowman, 2010).

\section{Levantamento bibliográfico de casos no mundo}

As mudanças na distribuição de vetores, são respostas das alterações nas funções bióticas e abióticas da resposta do ecossistema (Lieske \& Lloyd, 2018). No Brasil, a doença de Lyme foi descrita pela primeira vez em 1975 (Cordeiro et al., 2012). Em um estudo realizado em cães da região rural de 7 cidades do Rio de Janeiro, a prevalência total foi de 52,56\% para anticorpos contra B. burgdorferi (Cordeiro et al., 2012). Contudo, ainda não foi isolada a Borrelia burgdorferi nos tecidos humanos. Todavia, os doentes demonstraram uma alta frequência de autoanticorpos e então a enfermidade acabou recebendo outras denominações, tais como: DL-símile, Síndrome Infecto-Reacional Lyme-símile (SIRLS), doença de Lyme-símile Brasileira, para melhor diferenciar da Lyme clássica (Yoshinari et al., 2010). Um estudo realizado no estado do Paraná, concluiu que cães de áreas urbanas tiveram um maior risco de exposição a patógenos, quando comparados a cães de regiões rurais (Vieira et al., 2013).

Nos Estados Unidos, a distribuição da doença de Lyme é determinada por 2 vetores primários principais, o carrapato Ixodes scapularis e o Ixodes pacificus, estando concentrada no Nordeste e no meio oeste superior em torno da costa do Pacífico. Nessa localização, $40 \%$ dos canídeos saudáveis, podem testar positivo para o anticorpo para a B. burgdorferi (Borys et al., 2019). Em uma análise sorológica realizada em cães no leste dos EUA, foi confirmada a tendência crescente para Borrelia burgdorferi e Anaplasma spp. no Norte da Nova Inglaterra, norte de Nova York e no oeste da Pensilvânia, em alguns estados do sul (Dewage et al., 2019).

Em conformidade com Dewage et al. (2019) e Little et al. (2021) houve uma diminuição da soro prevalência e do total de casos humanos anuais em Connecticut, entre os anos de 2007 a 2019, região onde a doença de Lyme era endêmica. Já no Maine, os casos de DL continuam a aumentar, indicando relação com as ninfas de I. scapularis (Dewage et al., 2019). Em Delaware, Maine, New Hampshire e Vermont, os casos de borreliose humana e de cães soropositivos com o anticorpo de B. Burgdorferi, apresentaram uma relação maior do que a esperada (Little et al., 2021; Little et al., 2014). Uma explicação para a redução do número de casos de Lyme, é a influência no controle de carrapatos e o incentivo a vacinação contra a Borrelia burgdorferi, desse modo reduz a infecção canina (Dewage et al., 2019). Em um estudo realizado no Canadá entre 2008 - 2015, a Borrelia burgdorferi foi a bactéria mais comum e difundido pelos vetores caninos, com a soro prevalência mais elevada em Manitoba, Ontário, Quebec, New Brunswick e Nova Scotia. É válido que as variações geográficas e as diferenças de casos eram esperadas, devido a disparidade do clima (Evason et al., 2019). Utilizar os cães como sentinelas para esses patógenos, pode auxiliar no reconhecimento de uma ameaça à saúde pública e veterinária, já que a soro prevalência vem aumentando, dessa forma, ressalta que quanto maior for a determinação na gama de soro prevalência dos agentes, mais rápido alcançará o diagnóstico, consequentemente será mais fácil e necessária a conscientização e incentivo de medidas preventivas (Herrin et al., 2017).

\section{Conclusão}

A doença de Lyme, apesar de ser pouco diagnosticada, é uma enfermidade em ascensão. Deste modo, vale ressaltar a importância de levantamentos de dados sobre a história clínica dos pacientes, distribuição geográfica dos agentes transmissores dessa zoonose, protocolos de tratamentos, disseminando informações sobre, para realizar a profilaxia e prevenção contra essa patologia que expõe risco evidente à saúde pública.

\section{Agradecimentos}

Agradecemos a colaboração dos médicos veterinários Rodrigo Veroneze Domenech e Ivan Tonelotti de Carvalho Júnior pelo envio do teste sorológico. À mentora Amanda Duarte, por toda a ajuda e incentivo. À equipe da Kite Veterinária pela participação no atendimento do animal. 


\section{Declaração de conflito de interesses}

Os autores não declararam nenhum conflito de interesse neste relato de caso quanto à autoria e publicação deste artigo.

\section{Referências bibliográficas}

Baneth, G., Nachum-Biala, Y., Halperin, T., Hershko, Y., Kleinerman, G., Anug, Y., Abdeen, Z., Lavy, E., Aroch, I., \& Straubinger, R. K. (2016). Borrelia persica infection in dogs and cats: clinical manifestations, clinicopathological findings and genetic characterization. Parasites \& Vectors, 9(1), 1-10. https://doi.org/10.1186/s13071-016-1530-5.

Borys, M. A., Kass, P. H., Mohr, F. C., \& Sykes, J. E. (2019). Differences in clinicopathologic variables between Borrelia C6 antigen seroreactive and Borrelia C6 seronegative glomerulopathy in dogs. Journal of Veterinary Internal Medicine, 33(5), 2096-2104. https://doi.org/10.1111/jvim.15586.

Bowman, D. D. (2010). Parasitologia veterinária. Elsevier.

Burgess, E. C. (1986). Natural exposure of Wisconsin dogs to the Lyme disease spirochete (Borrelia burgdorferi). Laboratory Animal Science, 36(3), 288-290.

Cordeiro, M. D., Meireles, G. S., Silva, J. B., Souza, M. M. S., \& Fonseca, A. H. (2012). Soroprevalência para Borrelia spp. em cães no município de Seropédica, estado do Rio de Janeiro. Brazilian Journal of Veterinary Medicine, 34(3), 251-256.

Crivellentin, L. Z., \& Borin-Crivelletin, S. (2015). Casos de rotina em medicina veterinária de pequenos animais. In MedVet. MedVet.

Dewage, B. G., Little, S., Payton, M., Beall, M., Braff, J., Szlosek, D., Buch, J., \& Knupp, A. (2019). Trends in canine seroprevalence to Borrelia burgdorferi and Anaplasma spp. in the eastern USA, 2010-2017. Parasites \& Vectors, 12(1), 1-13. https://doi.org/10.1186/s13071-019-3735-X.

Elhelw, R., Elhariri, M., Hamza, D., Abuowarda, M., Ismael, E., \& Farag, H. (2021). Evidence of the presence of Borrelia burgdorferi in dogs and associated ticks in Egypt. BMC Veterinary Research, 17(1), 1-9. https://doi.org/10.1186/s12917-020-02733-5.

Evason, M., Stull, J. W., Pearl, D. L., Peregrine, A. S., Jardine, C., Buch, J. S., Lailer, Z., O’Connor, T., Chandrashekar, R., \& Weese, J. S. (2019). Prevalence of Borrelia burgdorferi, Anaplasma spp., Ehrlichia spp. and Dirofilaria immitis in Canadian dogs, 2008 to 2015: a repeat cross-sectional study. Parasites \& Vectors, 12(1), 64. https://doi.org/10.1186/s13071-019-3299-9.

EUA. Department of Health \& Human Services. CDC - Centers for Disease Control and Prevention: National Center for Emerging and Zoonotic Infectious Diseases (NCEZID), Division of VectorBorne Diseases (DVBD). "Classic Lyme disease rash" .9 jan. 2020. Disponível em: https://www.cdc.gov/lyme/signs_symptoms/rashes.html. Acesso em: 16 set. 2021

Ferreira, K. C., Moreno, E., Vieira, J. F., \& Carvalho, F. F. (2016). Suspeita de borreliose em cão em São Paulo/SP, Brasil. Relato de caso. Revista de Educação Continuada Em Medicina Veterinária e Zootecnia Do CRMV-SP, 14(3), 56.

Ford, R. B. (2001). Canine vaccination guidelines. Journal of the American Animal Hospital Association, 52(5), 243-251. https://doi.org/10.5326/JAAHA-MS-6741.

Fortes, E. (2004). Parasitologia veterinária (4th ed.). Editora ícone.

Galluzzo, P., Grippi, F., Di Bella, S., Santangelo, F., Sciortino, S., Castiglia, A., Sciacca, C., Arnone, M., Alduina, R., \& Chiarenza, G. (2020). Seroprevalence of Borrelia burgdorferi in stray dogs from southern Italy. Microorganisms, 8(11), 1688. https://doi.org/10.3390/microorganisms8111688.

Gettings, J. R., Lopez, J. E., Krishnavajhala, A., Armstrong, B. A., Thompson, A. T., \& Yabsley, M. J. (2019). Antibodies to Borrelia turicatae in experimentally infected dogs cross-react with Borrelia burgdorferi serologic assays. Journal of Clinical Microbiology, 57(9), e00628-19. https://doi.org/10.1128/JCM.00628-19.

Herrin, B. H., Peregrine, A. S., Goring, J., Beall, M. J., \& Little, S. E. (2017). Canine infection with Borrelia burgdorferi, Dirofilaria immitis, Anaplasma spp. and Ehrlichia spp. in Canada, 2013-2014. Parasites \& Vectors, 10(1), 1-9. https://doi.org/10.1186/s13071-017-2184-7. 
Irwin, P. J., Robertson, I. D., Westman, M. E., Perkins, M., \& Straubinger, R. K. (2017). Searching for Lyme borreliosis in Australia: results of a canine sentinel study. Parasites \& Vectors, 10(1), 1-9. https://doi.org/10.1186/s13071-017-2058-z.

Izac, J. R., \& Marconi, R. T. (2019). Diversity of the lyme disease spirochetes and its influence on immune responses to infection and vaccination. Veterinary Clinics: Small Animal Practice, 49(4), 671-686. https://doi.org/10.1016/j.cvsm.2019.02.007.

Kassab, S., Dankar, E., Pereira, J., Ferreira, L. A., \& Montozo, M. F. (2020). Borreliose canina. Encicloédia Bioesfera, 17(32), 160-178. https://doi.org/10.18677/EnciBio_2020B13.

Lappin, M. R., Chandrashekar, R., Stillman, B., Liu, J., \& Mather, T. N. (2015). Evidence of Anaplasma phagocytophilum and Borrelia burgdorferi infection in cats after exposure to wild-caught adult Ixodes scapularis. Journal of Veterinary Diagnostic Investigation, 27(4), 522-525.

Lieske, D. J., \& Lloyd, V. K. (2018). Combining public participatory surveillance and occupancy modelling to predict the distributional response of Ixodes scapularis to climate change. Ticks and Tick-Borne Diseases, 9(3), 695-706. https://doi.org/10.1016/j.ttbdis.2018.01.018

Little, S. E., Beall, M. J., Bowman, D. D., Chandrashekar, R., \& Stamaris, J. (2014). Canine infection with Dirofilaria immitis, Borrelia burgdorferi, Anaplasma spp., and Ehrlichia spp. in the United States, 2010-2012. Parasites \& Vectors, 7(1), 1-9. https://doi.org/10.1186/s13071-020-04514-3.

Little, S. E., Braff, J., Place, J., Buch, J., Dewage, B. G., Knupp, A., \& Beall, M. (2021). Canine infection with Dirofilaria immitis, Borrelia burgdorferi, Anaplasma spp., and Ehrlichia spp. in the United States, 2013-2019. Parasites \& Vectors, 14(1), 1-16.

Littman, M. P., Goldstein, R. E., Labato, M. A., Lappin, M. R., \& Moore, G. E. (2006). ACVIM small animal consensus statement on Lyme disease in dogs: diagnosis, treatment, and prevention. Journal of Veterinary Internal Medicine, 20(2), 422-434.

Liu, Y., Nordone, S. K., Yabsley, M. J., Lund, R. B., McMahan, C. S., \& Gettings, J. R. (2019). Quantifying the relationship between human Lyme disease and Borrelia burgdorferi exposure in domestic dogs. Geospatial Health, 14(1). https://doi.org/10.4081/gh.2019.750.

Maluf Júnior, I., Zahdi, M. R., Bonalumi Filho, A., \& Cruz, C. R. (2007). Doença de Lyme: diagnóstico e tratamento. Revista Brasileira de Medicina de Família e Comunidade, 3(10), 76-81.

Marconi, R. T., Garcia-Tapia, D., Hoevers, J., Honsberger, N., King, V. L., Ritter, D., Schwahn, D. J., Swearingin, L., Weber, A., \& Winkler, M. T. C. (2020). VANGUARD® crLyme: A next generation Lyme disease vaccine that prevents B. burgdorferi infection in dogs. Vaccine: X, 6, 100079. https://doi.org/10.1016/j.jvacx.2020.100079.

Moraillon, R., Legeay, Y., Boussarie, D., \& Sénécat, O. (2013). Manual Elsevier de Veterinária: Diagnóstico e tratamento de cães, gatos e animais exóticos (7th ed.). Elsevier.

Murray, T., \& Feder, H. M. (2001). Management of tick bites and early Lyme disease: a survey of Connecticut physicians. Pediatrics, 108(6), 1367-1370.

Nelson, R. W., \& Couto, C. G. (2015). Medicina interna de pequenos animais (Issue 1). Elsevier Editora.

Oldenburg, D. G., Jobe, D. A., Lovrich, S. D., LaFleur, R. L., White, D. W., Dant, J. C., \& Callister, S. M. (2020). Detection of antibodies to decorin-binding protein A (DbpA) and DbpB after infection of dogs with Borrelia burgdorferi by tick challenge. Journal of Veterinary Diagnostic Investigation, 32(3), 481-485. https://doi.org/10.1177/1040638720912394

Rabelo, R. (2012). Emergências em pequenos animais: Condutas clínicas e cirúrgicas no paciente grave. Elsevier Brasil.

Schreiber, C., Krücken, J., Beck, S., Maaz, D., Pachnicke, S., Krieger, K., Gross, M., Kohn, B., \& von Samson-Himmelstjerna, G. (2014). Pathogens in ticks collected from dogs in Berlin/Brandenburg, Germany. Parasites \& Vectors, 7(1), 1-10. https://doi.org/10.1186/s13071-014-0535-1.pdf

Spinosa, H. S. S., Górniak, S. L., \& Bernardi, M. M. (2017). Farmacologia aplicada à medicina veterinária. Koogan Guanabara.

Tilley, L. P., Smith, J. R., \& Francis, W. K. (2008). Consulta veterinária em 5 minutos: Espécies canina e felina. Editora Manole. 
Tilley, L. P. (2008). Manual of canine and feline cardiology. Elsevier Health Sciences.

Toepp, A. J., Willardson, K., Larson, M., Scott, B. D., Johannes, A., Senesac, R., \& Petersen, C. A. (2018). Frequent exposure to many hunting dogs significantly increases tick exposure. Vector-Borne and Zoonotic Diseases, 18(10), 519-523. https://doi.org/10.1089/vbz.2017.2238.

Vaden, S. L., Kno, L., S., J., Smith, J. R., Francis, W. K., \& Tilley, L. P. (2013). Sorologia para doença de Lyme: Explanação sobre o teste e fisiologia relacionada. In T. Wheeler (Ed.), Exames laboratoriais e procedimentos diagnósticos em cães e gatos (pp. 934-937). Roca, Brasil.

Vieira, T. S. W. J., Vieira, R. F. da C., Nascimento, D. A. G., Tamekuni, K., Toledo, R. dos S., Chandrashekar, R., Marcondes, M., Biondo, A. W., \& Vidotto, O. (2013). Serosurvey of tick-borne pathogens in dogs from urban and rural areas from Paraná State, Brazil. Revista Brasileira de Parasitologia Veterinária, 22(1), 104-109.

Yoshinari, N. H., Mantovani, E., Bonoldi, V. L. N., Marangoni, R. G., \& Gauditano, G. (2010). Doença de lyme-símile brasileira ou síndrome baggioyoshinari: zoonose exótica e emergente transmitida por carrapatos. Revista Da Associação Médica Brasileira, 56, 363-369.

Histórico do artigo:

Recebido: 29 de outubro de 2021

Aprovado: 22 de novembro de 2021

Disponível online: 28 de fevereiro de 2022
Licenciamento: Este artigo é publicado na modalidade Acesso Aberto sob a licença Creative Commons Atribuição 4.0 (CC-BY 4.0), a qual permite uso irrestrito, distribuição, reprodução em qualquer meio, desde que o autor e a fonte sejam devidamente creditados. 